\title{
A comparative study of intramuscular sulfate versus intravenous magnesium injection among eclampsia patients in Eastern, Uttar Pradesh, India
}

\author{
Uzma Kauser, Anjali Chaudhari*
}

Department of Obstetrics and Gynecology, MRA Medical College Ambedkarnagar, Uttar Pradesh, India

Received: 17 January 2020

Revised: 15 February 2020

Accepted: 28 February 2020

\author{
*Correspondence: \\ Dr. Anjali Chaudhari, \\ E-mail: njmsonline@gmail.com
}

Copyright: (c) the author(s), publisher and licensee Medip Academy. This is an open-access article distributed under the terms of the Creative Commons Attribution Non-Commercial License, which permits unrestricted non-commercial use, distribution, and reproduction in any medium, provided the original work is properly cited.

\begin{abstract}
Background: Hypertensive in pregnancy is the second most common cause of maternal mortality in India. Among the hypertensive disorders that complicate pregnancy, pre-eclampsia and eclampsia stand out as major causes of maternal and perinatal mortality and morbidity. The majority of deaths due to pre-eclampsia and eclampsia are avoidable through the provision of timely and effective care to the women presenting with these complications. Objectives of this study were to find out the effectiveness of intravascular and intramuscular magnesium sulfate in management of eclampsia. To compare the side effects and complications of intravascular and intramuscular magnesium sulfate in management of eclampsia.

Methods: A total 100 patients presenting with eclamptic fits reporting to the center that has been included in the study. The study has been conducted in the labor room of Nehru Chikitsalaya of B. R. D. Medical College, Gorakhpur, Uttar Pradesh for 12 months duration period. Statistical analysis of observations has been done by Chisquare test with $\mathrm{p}$-value $<0.05$ has been considered in the study.

Results: Majority of eclampsia patients belonged to 20-25 years age group (63\%) followed by above 30 years of age (22\%). Nearly $16 \%$ patients in $\mathrm{IM} \mathrm{MgSO}_{4}$ group and $12 \%$ patients in $\mathrm{IV} \mathrm{MgSO}_{4}$ received recurrence of seizure after starting of treatment ( $p$ value $>0.5$ ). About $26 \%$ patients in $\mathrm{IM} \mathrm{MgSO}_{4}$ group and $18 \%$ patients in $\mathrm{IV} \mathrm{MgSO}_{4} \mathrm{group}$ had mild side effects of $\mathrm{MgSO} 4$ but no patients in both the group had major side effects of $\mathrm{MgSO}_{4}$.

Conclusions: The study concludes that intramuscular injection of $\mathrm{MgSO}_{4}$ is painful and the chances of abscess formation that's why compliance of intramuscular $\mathrm{MgSO}_{4}$ is not very good in compared to intravascular infusion of $\mathrm{MgSO}_{4}$. The chances of $\mathrm{Mg}$ toxicity are more $\mathrm{MgSO}_{4}$ regimen because of the dose required in $\mathrm{IM} \mathrm{MgSO}_{4}$ regimen is more (44gm) that of $\mathrm{IV} \mathrm{MgSO}_{4}(28 \mathrm{gm})$.
\end{abstract}

Keywords: Eclampsia, Maternal morbidity, Maternal mortality, Pregnancy complication

\section{INTRODUCTION}

Hypertensive disorders of pregnancy are an important cause of severe morbidity, long-term disability and death among both mothers and their babies. Worldwide, they account for approximately $14 \%$ of all maternal deaths, whereas in Latin America and the Caribbean, they contribute to approximately $22 \%$ of all maternal deaths. ${ }^{1}$
Among the hypertensive disorders that complicate pregnancy, pre-eclampsia and eclampsia stand out as major causes of maternal and perinatal mortality and morbidity. The majority of deaths due to pre-eclampsia and eclampsia are avoidable through the provision of timely and effective care to the women presenting with these complications. An estimated 0.5 million or more women die each year from complications of pregnancy 
and $95 \%$ of these women are in Africa and Asia. ${ }^{2}$ Eclampsia accounts for about $12 \%$ of maternal deaths in the world and $8 \%$ of maternal deaths in India. ${ }^{3,4}$ Magnesium sulfate has been used for the treatment of eclampsia since 1906 and has been popular for over 70 years in the USA. ${ }^{5,6}$ It has not been widely used in many countries, however, including India. In eastern India, magnesium sulfate was introduced in the treatment of eclampsia in the late 1990s following the publication of the multi-centric collaborative eclampsia Trial in 1995..$^{7-9}$ The collaborative eclampsia trial conclusively proved that magnesium sulfate is the drug of choice for the anticonvulsant management of women with eclampsia, rather than diazepam or phenytoin. The use of this drug reduced maternal deaths to $4.0 \%$ and the recurrence rate of convulsion was reduced by $52 \%$ and $67 \%$ when compared with diazepam and phenytoin, respectively. ${ }^{6}$

The use and apparent success of the magnesium sulfate regimen in the treatment of eclampsia is empirical, however. ${ }^{10,11}$ The two most widely used regimens of magnesium sulfate administration are the intramuscular IM regimen popularized by Pritchard and the continuous IV regimen recommended by Zuspan. ${ }^{10,12}$ Magnesium sulfate therapy has been associated with increased length of labor, an increased caesarean delivery rate, increased postpartum bleeding, increased respiratory depression, decreased neuromuscular transmission and maternal death from overdose. ${ }^{13}$ Since 1998 , the IM magnesium sulfate regimen has been popular in this hospital for the treatment of women with eclampsia.

\section{Objectives}

- To find out the effectiveness of intravascular and intramuscular magnesium sulfate in management of eclampsia.

- To compare the side effects and complications of intravascular and intramuscular magnesium sulfate in management of eclampsia.

\section{METHODS}

A total 100 eclampsia patients admitted in obstetrics and gynecology department of Nehru Chikitsalaya of B. R. D. Medical College, Gorakhpur, Uttar Pradesh, India. A total duration of this study was 12 months (from $1^{\text {st }}$ August 2017 to $31^{\text {st }}$ July 2018).

\section{Inclusion criteria}

- Eclampsia patients admitted in B. R. D. Medical College, Gorakhpur with exception in that magnesium sulfate is contraindicated.

\section{Exclusion criteria}

- $\quad$ Patients with known case of epilepsy

- In those where magnesium sulfate is contraindicated.

\section{Methodology of the data collection}

After institutional ethical committee approval and obtaining informed consent from patients, 100 patients presenting with eclamptic fits reporting to the center that has been included in the study. The study has been conducted in the labor room of Nehru Chikitsalaya of B. R. D. Medical College, Gorakhpur, Uttar Pradesh for 12 months duration period. Patients who had been admitted with eclampsia in the labor room, a complete history, general examination, central nervous system, cardiovascular system, respiratory system and obstetrical examination has been done. Also, those patients who presented with history of previous seizure disorders and patients in whom magnesium sulfate was contraindicated (oliguria or renal failure, hypocalcaemia states, myasthenia gravis, cardiac conditions in particular conduction disorders or myocardial damage) which has been excluded and rest of patients were recruited for the study after informed written consent. Then, the recruited patients were randomly selected for intravascular or intramuscular regimen of magnesium sulfate.

\section{Continuous intravenous infusion}

- 4 gm of loading dose of magnesium sulfate diluted in $100 \mathrm{ml}$ of intravenous fluid (normal saline) administered over 15-20 minutes.

- 12 ampule magnesium sulfate in $1 \mathrm{~L}$ of normal saline solutions at 28 drops/ minute (total 24 hours), after 12 hours similar bottle of magnesium sulfate infusion. This provides $\mathrm{MgSO}_{4}$, at $1 \mathrm{gm} / \mathrm{hr}$.

- Monitoring for magnesium toxicity:

- Asses deep tendon reflexes periodically (4 hourly)

- Measure urine output hourly

- Respiratory rate hourly.

- Magnesium sulfate is discontinued for 24 hours after delivery or last convulsion which one is later.

\section{Intermittent intramuscular injections}

- $\quad 4 \mathrm{mg}$ of magnesium sulfate has been given as $20 \%$ solution intravenously at the rate not exceed 1 gm/minute.

- Follow promptly with $10 \mathrm{gm}$ of $50 \%$ magnesium sulfate solution, one half ( $5 \mathrm{gm}$ ) injected deeply in the upper outer quadrant of both buttocks through the 3 -inch-long gauge needle, if convulsion persists after 15 minutes which has been given $1 \mathrm{gm} /$ minute.

- Every four hours there after $5 \mathrm{gm}$ of $50 \%$ solution of magnesium sulfate has been given deeply in outer upper quadrant of alternate buttocks but only after ensuring that:

- Patellar reflex was present

- Respiration were not depressed

- Urine output of the previous 4 hours exceeded $100 \mathrm{ml}$. 
- Magnesium sulfate discontinued in 24 hours after the delivery.

\section{Examination of patients}

- Abdominal examination, per vaginal examination $(\mathrm{p} / \mathrm{v})$ has been done and BISHOP score has been recorded and completed the investigations (ABG, $\mathrm{ABO} / \mathrm{Rh}, \mathrm{Hb}, \mathrm{TLC}, \mathrm{DLC}, \mathrm{HIV}, \mathrm{HBsAg}, \mathrm{HCV}$, CDRL, LFT, KFT, RBS, LDH, GBP with platelets count, prothrombin time and INR has been also taken. The patient has been chosen for caesarean section or induction of labor depending on maternal, fetal conditions and Bishop score.

- The patient who has been selected for induction of labor, continuous fetal monitoring by CTG and progression of labor has been recorded by partogram as per World Health Organization (WHO) guidelines.
- The vitals of all patients have been recorded continuously by multichannel monitor (pulse rate, blood pressure, respiratory rate, temperature, saturation, urine output).

\section{Statistical analysis}

Statistical analysis of observations has been done by Chisquare test with $\mathrm{p}$-value $<0.05$ has been considered in the study.

\section{RESULTS}

During the study period, the total number of deliveries was 3294 and total number of eclampsia was 328. Therefore, the incidence of eclampsia was 9.95\% (Table 1). The total eclampsia patients have been selected in the present study and divided into two sub-groups, i.e. IM $\mathrm{MgSO}_{4}$ groups and $\mathrm{IV} \mathrm{MgSO}_{4}$ groups (Figure 1).

Table 1: Incidence of eclampsia during the study period.

\begin{tabular}{|c|c|c|c|}
\hline Time period & $\begin{array}{l}\text { Total number of } \\
\text { deliveries }\end{array}$ & $\begin{array}{l}\text { Total number of } \\
\text { eclampsia }\end{array}$ & $\begin{array}{l}\text { Incidence of } \\
\text { eclampsia }\end{array}$ \\
\hline $1^{\text {st }}$ August 2017 to $31^{\text {st }}$ July 2018 & 3294 & 328 & $9.95 \%$ \\
\hline
\end{tabular}

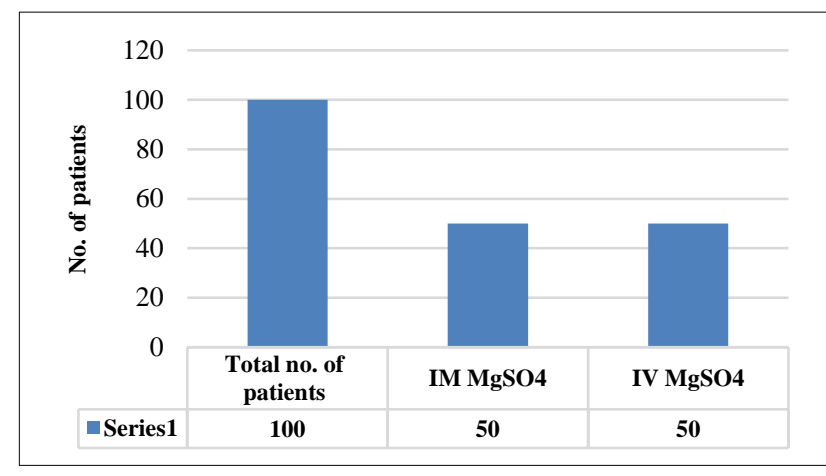

Figure 1: Total patients of eclampsia selected in the study.

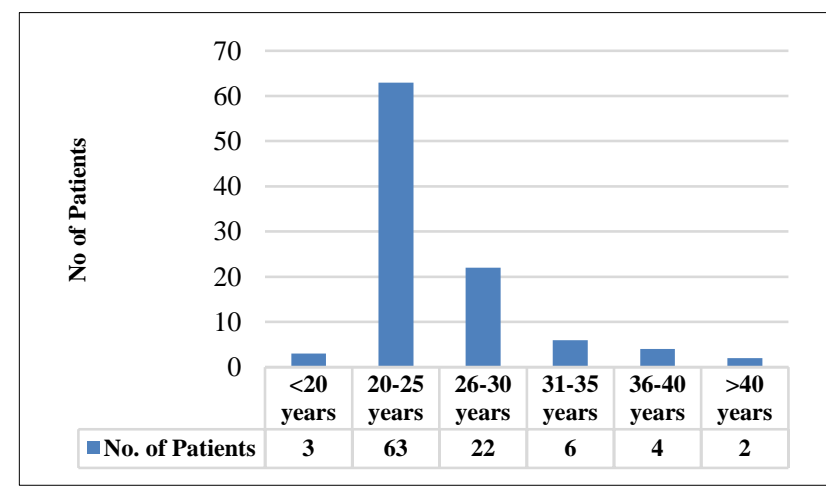

Figure 2: Age-wise distribution of patients presenting with eclampsia.
The Figure 2 indicates the distribution of age groups among eclampsia patients. The maximum number of eclampsia patients (63\%) among 20-25 years age groups.

Around 22\% eclampsia patients were above 30 years of age and only $3 \%$ patients were accounted for the age group below 20 years.

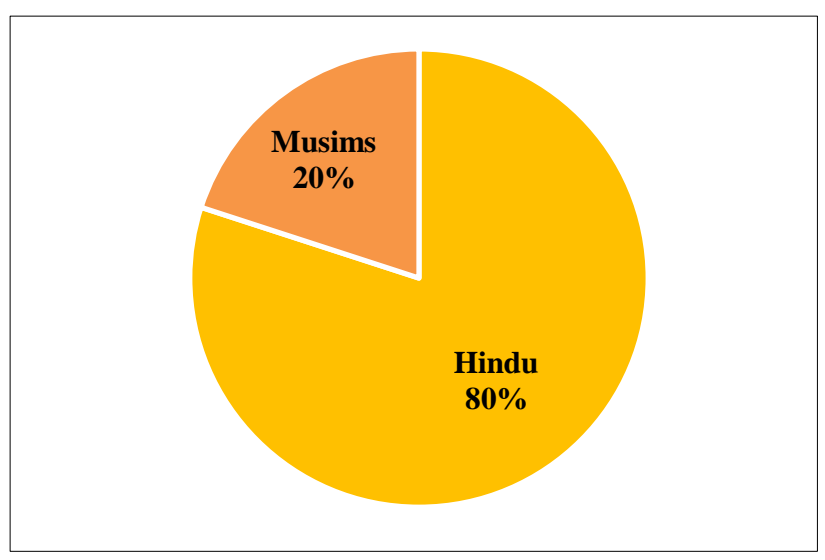

Figure 3: Religion wise distribution of patients presenting with eclampsia.

The Figure 3 explains the religion compositions among eclampsia patients. This shows that majority of eclampsia patients were Hindus that have been accounted for $80 \%$ whereas Muslims were accounted for only $20 \%$. 
The Figure 4 shows that the majority of eclampsia patients were belong to rural areas which have been accounted for $71 \%$ whereas remaining $26 \%$ belonged to urban areas.

The Figure 5 shows that the majority of eclampsia patients belonged to lower middle socio-economic status.

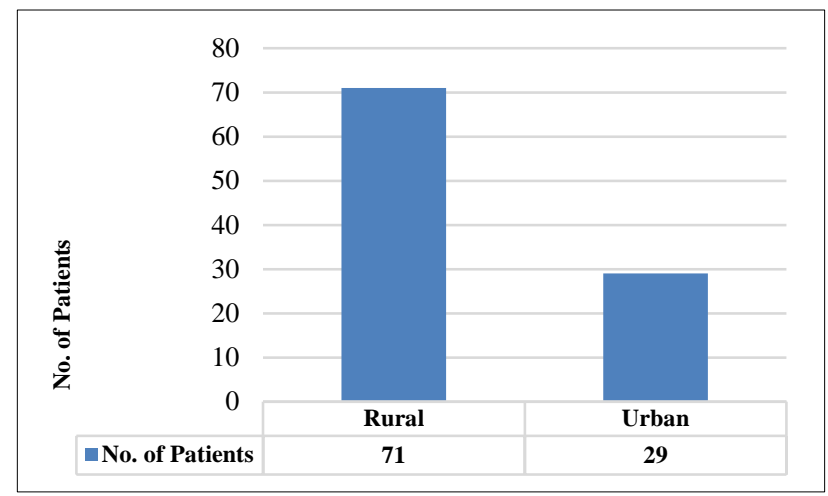

Figure 4: Distribution of eclampsia patients by place of residence.

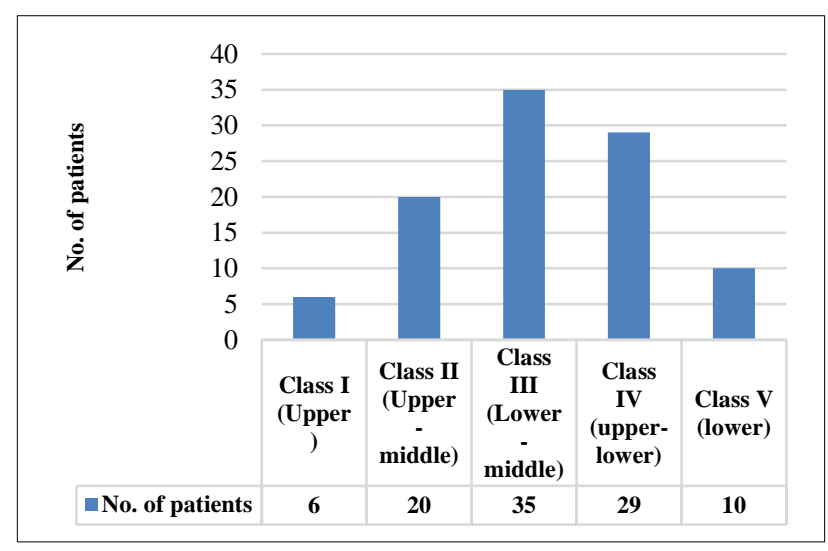

Figure 5: Distribution of patients presenting with eclampsia according to their socio-economic status (Kuppuswamy's classification).

Around $35 \%$ belonged to class III and $29 \%$ belonged to class IV.

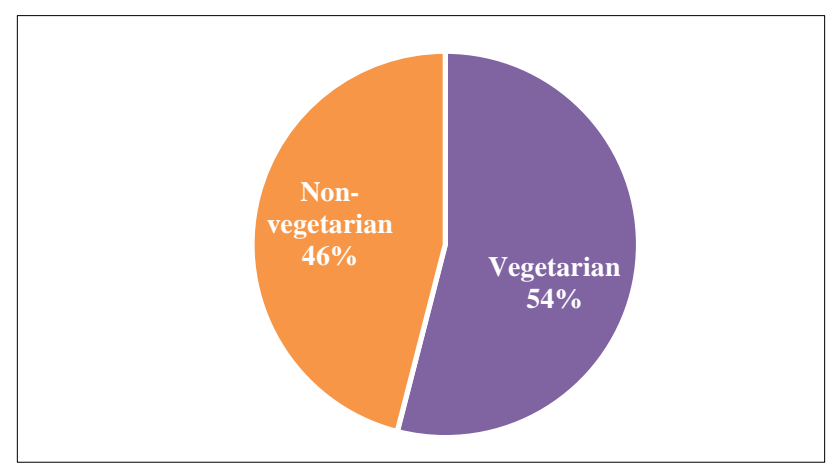

Figure 6: Distribution of patients presenting with eclampsia according to their dietary habit.
The Figure 6 shows that the majority of eclampsia patients were vegetarian which have been accounted for $54 \%$ whereas rest $46 \%$ were non-vegetarian.

The Figure 7 shows that the majority $31 \%$ eclampsia patients were illiterate, rest were educated up to primary $25 \%$, middle class $20 \%$, high school $10 \%$, intermediate $7 \%$, graduation $7 \%$.

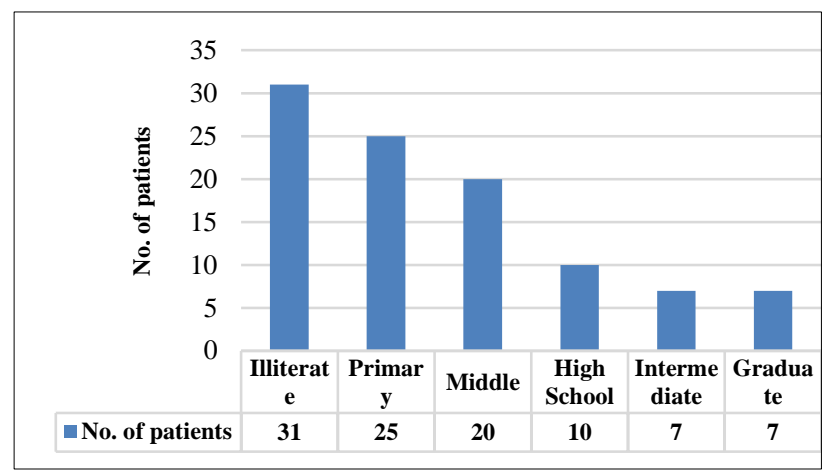

Figure 7: Distribution of patients presenting with eclampsia according to education level.

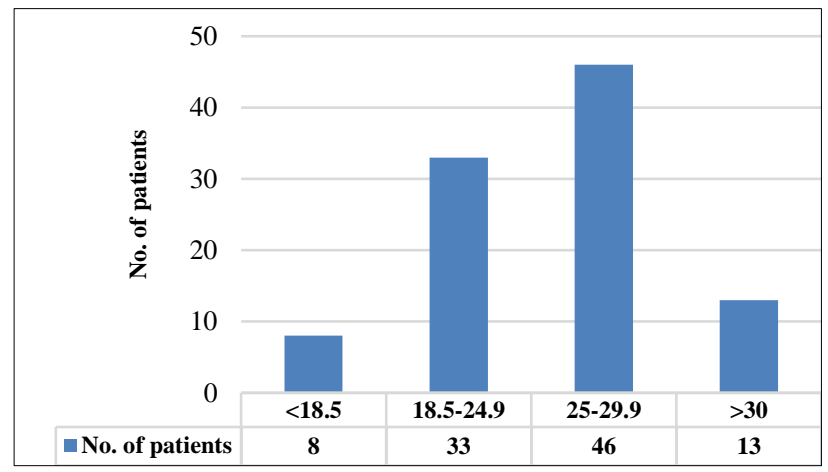

Figure 8: Distribution of patients presenting with eclampsia according to their body mass index (BMI taken days after delivery).

The Figure 8 shows the distribution of patients presenting with eclampsia according to their BMI. There were 59\% eclampsia patients who had BMI $>25$ and rest $41 \%$ has BMI $<25$.

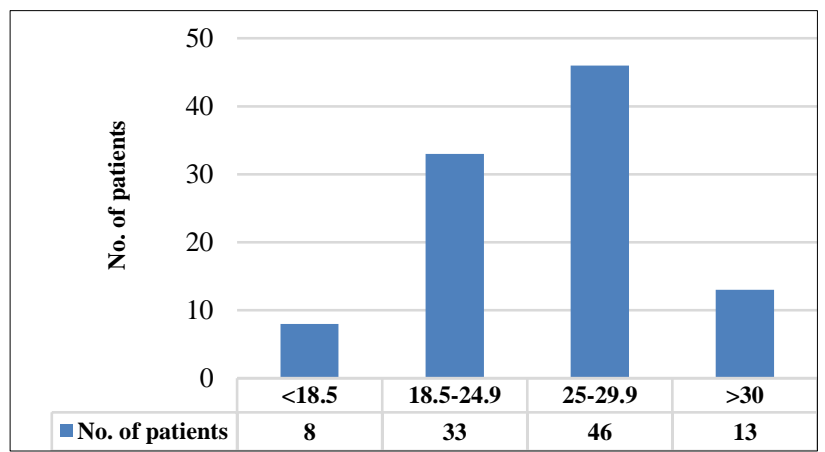

Figure 9: Distribution of patients presenting with eclampsia according to the type of eclampsia. 
The Figure 9 represents that the majority of patients were $54 \%$, presented as antepartum eclampsia, $28 \%$ as intrapartum and only $18 \%$ presented with post-partum eclampsia. The Figure 10 represents that the majority of patients $91.11 \%$ in IM group and $91.89 \%$ in IV $\mathrm{MgSO}_{4}$ group presented with fetal heart sound and rest patients presented with intrauterine death.

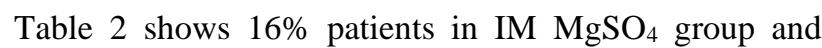
$12 \%$ patients in $\mathrm{IV}_{\mathrm{MgSO}_{4}}$ received recurrence of seizure after starting of treatment with $\mathrm{p}$ value 0.564 , which is insignificant. Table 3 shows $26 \%$ patients in $\mathrm{IM} \mathrm{MgSO}_{4}$ group and $18 \%$ patients in IV $\mathrm{MgSO}_{4}$ group had mild side effect of $\mathrm{MgSO}_{4}$ but no patients in both the group had major side effects of $\mathrm{MgSO}_{4}$.

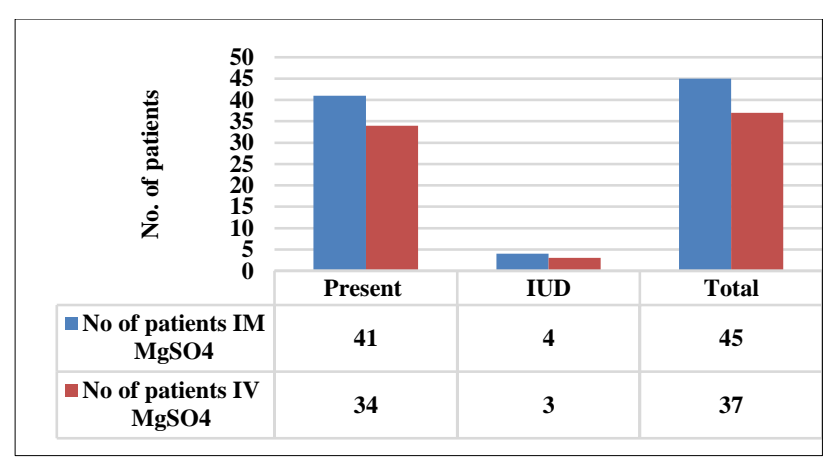

Figure 10: Distribution of patients in $\mathrm{IM} \mathrm{MgSO}_{4}$ and IV $\mathrm{MgSO}_{4}$ group patients according to fetal heart present during admission.

Table 2: Incidence of repeat seizure in $\mathrm{IM} \mathrm{MgSO}_{4}$ and $\mathrm{IV} \mathrm{MgSO}_{4}$ group in eclampsia patients after starting of treatment.

\begin{tabular}{|c|c|c|c|c|c|}
\hline & \multicolumn{2}{|l|}{$\mathrm{IM} \mathrm{MgSO}_{4}$} & \multicolumn{2}{|l|}{ IV $\mathrm{MgSO}_{4}$} & \multirow{2}{*}{ p-value } \\
\hline & No. of patients & Percentage & No. of patients & Percentage & \\
\hline Repeated seizures & 8 & $16 \%$ & 6 & $12 \%$ & 0.564 \\
\hline Total & 50 & $100 \%$ & 50 & $100 \%$ & \\
\hline
\end{tabular}

Table 3: Comparison of $\mathrm{IM} \mathrm{MgSO}_{4}$ and IV $\mathrm{MgSO}_{4}$ regimen according to their side effect of $\mathrm{MgSO}_{4}$ in eclampsia patients.

\begin{tabular}{|lllll|}
\hline Side effects of $\mathrm{MgSO}_{4}$ & IM MgSO & & IV \\
\hline & No. of patients & Percentage & No. of patients & Percentage \\
\hline $\begin{array}{l}\text { Mild (flushing of skin, sensation of pain or } \\
\text { warmth in arms nausea) }\end{array}$ & 13 & $26 \%$ & 9 & $18 \%$ \\
\hline $\begin{array}{l}\text { Severe (loss of reflexes, respiratory depression, } \\
\text { muscles paralysis, blurred or double vision, } \\
\text { slurred speech, cardiac conduction changes, } \\
\text { cardiac arrest). }\end{array}$ & 0 & $0 \%$ & 0 & $0 \%$ \\
\hline Total & 50 & $100 \%$ & 50 & $100 \%$ \\
\hline
\end{tabular}

\section{DISCUSSION}

Eclampsia is a life-threatening complication of hypertensive disorders of pregnancy. It is a major cause of maternal mortality, perinatal mortality and morbidity. They study has shown that incidence rate is very high as this medical institute is a tertiary center and the referral cases are higher. During the study period from $1^{\text {st }}$ August 2017 to $31^{\text {st }}$ July 2018 , out of total 3294 deliveries, there was 241 cases were antepartum eclampsia and 87 cases were postpartum eclampsia (total eclampsia cases were 328). Thus, incidence of eclampsia is $9.95 \%$. The study shown that incidence of eclampsia in eastern India has been reported with $3.2 \% .^{14}$ Study has reported that incidence as high as $9 \%$ in their study at a tertiary center in Bangladesh. ${ }^{15,16}$ In a study, there were 44 cases of eclampsia in the University hospital Institute of medical sciences of BHU (Varanasi), the incidence was reported as $22 / 1000 .{ }^{17}$ The total 100 eclampsia patients have been selected in the present study and divided into two subgroups, i.e. IM $\mathrm{MgSO}_{4}$ groups and IV $\mathrm{MgSO}_{4}$ groups. The present study shown that the maximum number of patients belongs to 20-25 years age group where $22 \%$ eclampsia patients belonged to the age group 26-30 years and there were only $12 \%$ patients above 30 years and only $3 \%$ patients were below 20 years age. This low age is indicative of the fact that girls are still married at an early age particularly in low socio-economic status. Another study has reported that the mean age of eclampsia incidence is 18.5 years. ${ }^{13}$

The present study revealed that majority of eclampsia patients were Hindus that have been accounted for $80 \%$ whereas Muslims were accounted for only $20 \%$. And the majority of eclampsia patients were belonging to rural areas which have been accounted for $71 \%$ whereas remaining $26 \%$ belonged to urban areas. The study also 
explained that the majority of eclampsia patients belonged to lower middle socio-economic status. Around $35 \%$ belonged to class III and $29 \%$ belonged to class IV. Previous study has found that $100 \%$ cases of eclampsia belonged to low socio-economic status. ${ }^{18}$ The majority $31 \%$ eclampsia patients were illiterate, rest were educated up to primary $25 \%$, middle class $20 \%$, high school $10 \%$, intermediate $7 \%$, graduation $7 \%$. Previous study observed that maximum cases of eclampsia is illiterate group $(37.61 \%)$ followed by primary education $(27.08 \%)$ and high school (31.19\%).

The distribution of patients presenting with eclampsia according to their BMI. There were 59\% eclampsia patients who had BMI $>25$ and rest $41 \%$ has BMI $<25$. The present study revealed that majority of patients $91.11 \%$ in IM group and $91.89 \%$ in IV $\mathrm{MgSO}_{4}$ group presented with fetal heart sound and rest patients presented with intrauterine death. This shows $16 \%$

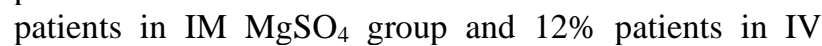
$\mathrm{MgSO}_{4}$ received recurrence of seizure after starting of treatment with $\mathrm{p}$ value 0.564 , which is insignificant. The study revealed that there are $26 \%$ patients in $\mathrm{IM} \mathrm{MgSO}_{4}$ group and $18 \%$ patients in IV $\mathrm{MgSO}_{4}$ group had mild side effect of $\mathrm{MgSO}_{4}$ but no patients in both the group had major side effects of $\mathrm{MgSO}_{4}$.

\section{CONCLUSION}

The study concludes that the pritchard regimen and IV continuous $\mathrm{MgSO}_{4}$ regimen (Zuspan regimen) are equally effective in controlling maternal and fetal side effects which were equally low. Intramuscular injection of $\mathrm{MgSO}_{4}$ is painful and the chances of abscess formation that's why compliance of intramuscular $\mathrm{MgSO}_{4}$ is not very good in compared to intravascular infusion of $\mathrm{MgSO}_{4}$. The chances of $\mathrm{Mg}$ toxicity are more $\mathrm{MgSO}_{4}$ regimen because of the dose required in $\mathrm{IM} \mathrm{MgSO}_{4}$

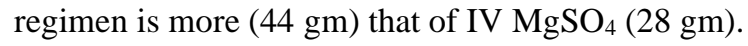

\section{Funding: No funding sources}

Conflict of interest: None declared

Ethical approval: The study was approved by the Institutional Ethics Committee

\section{REFERENCES}

1. Say L, Chou D, Gemmill A, Tunçalp Ö, Moller AB, Daniels $J$, et al. Global causes of maternal death: a WHO systematic analysis. The Lancet Global Health. 2014;2(6):e323-33.

2. Abou Zahr C, Wardlaw TM, Choi Y. Maternal mortality in 2000: estimates developed by WHO, UNICEF and UNFPA. World Health Organization; 2004.
3. Murray CJL, Lopez AD III. Health dimensions of sex and reproduction. Global Burden of Disease and Injury Series. Cambridge, MA: Harvard School of Public Health; 1998.

4. Ministry of Health and Family Welfare, India. Annual Report. New Delhi: Ministry of Health and Family Welfare, India. 2005:105-11.

5. Chesley LC, Wynn RM. Hypertensive disorders in pregnancy. New York: Appleton-Century-Crofts; 1978.

6. The Eclampsia Trial Collaborative Group. Which anticonvulsant for women with eclampsia? Evidence from the collaborative eclampsia trial. Lancet. 1995;345:1459-69.

7. Majhi AK, Chakraborty PS, Mukhopadhyay A. Eclampsia: Present scenario in a referral medical college hospital. J Obstet Gynaecol India. 2001;51:1437 .

8. Saha S, Ghosh Roy S, Ganguly RP, Das A. Comparative study on the efficacy of magnesium sulphate and diazepam in the management of eclampsia in a peripheral rural medical college (A cross over study of 440 cases). J Obstet Gynaecol India. 2002;52:69-72.

9. Datta MR, Pant L, Kabiraj M, Basu SB. Magnesium sulphate in eclampsia: A safe, efficient and costeffective approach. J Obstet Gynecol. 2002;52:65-8.

10. Pritchard JA, Cunningham FG, Pritchard SA. The Parkland Hospital protocol for treatment of eclampsia: Evaluation of 245 cases. Am J Obstet Gynecol. 1984;148:951-63

11. Lucas MJ, Leveno JK, Cunningham FG. A comparison of Magnesium sulfate with Phenytoin for the prevention of eclampsia. N Engl J Med. 1995;334:201-6.

12. Zuspan FP. Treatment of severe preeclampsia and eclampsia. Clin Obstet Gynecol. 1966;9:954-72.

13. Sibai BM. Magnesium sulphate therapy in preeclampsia and eclampsia. Obstet Gynaecol. 1998;92:883-9.

14. Singh S, Behera A. Eclampsia in Eastern India: incidence, demographic profile and response to three different anticonvulsant regimes of magnesium sulphate. Internet J Gynecol Obstet. 2010;15(2):7708.

15. Begum MR, Begum A, Quadir E, Akhter S, Shamsuddin L. Eclampsia still a problem in Bangladesh. Med Gen Med. 2004;6:52.

16. Begum MR, Begum A, Quadir E. Loading dose versus standard regime of magnesium sulfate in the management of eclampsia: a randomized controlled trial. J Obstet Gynaecol Res. 2002;28:154-9.

17. Hatjis CG, Swain M. Systemic tocolysis for premature labor is associated with an increased incidence of pulmonary edema in the presence of maternal infection. Am J Obstet Gynecol. 1988;159(3):723-8.

18. Jamila $G$, Naila $S$, Afat $H$. The effectiveness of complex prevention of preeclampsia using immunoglobulins. J Multidiscipli Dis. 2019;37(2):11-6.

Cite this article as: Kauser U, Chaudhari A. A comparative study of intramuscular sulfate versus intravenous magnesium injection among eclampsia patients in Eastern, Uttar Pradesh, India. Int J Reprod Contracept Obstet Gynecol 2020;9:2470-5. 